\section{Top of the pops - CD-ROM and DVDs in dental education}

\author{
K. A. Eaton, ${ }^{1}$ P. A. Reynolds ${ }^{2}$ and M. J. Cox ${ }^{3}$
}

IN BRIEF
- CD-ROMs and DVDs have been used in
dental education for several years.
If they are well designed, they will deliver
information using a range of media and
interaction with the user.
- They can used to provide pre-course
information (theory) prior to hands-on
(practical) courses or as revision aids to
those preparing for examinations.

In many ways the CD-ROM was the first digital teaching aid, the precursor of what was to develop into e-learning. Launched in the mid-1980s, its first educational application was as a storage medium for reference material. Since then the list of its uses has grown as has its storage capacity, ability to hold data in different formats - text, audio image and video - and its interactive properties have allowed developers to produce discs which enhance both the processes and enjoyment of teaching and learning. In this article the stages involved in production of an educational CD-ROM, typical content and the benefits are considered, prior to a review of a number discs that have been used in dental education. The varied titles reveal how versatile CD-ROMs can be. They range from a course showing students the importance of good patient communications and how to achieve them, to an in-depth exposition in the 'Head and Neck Anatomy' disc, a subject important not just for dentistry, but for other medical disciplines as well. The last section of this article considers a study undertaken amongst its students by the Open University, which investigated the effectiveness of CD-ROM in education. In conclusion, it can be said that although the CD-ROM format is a versatile, popular and valuable aid, with the emergence of DVD it may soon be seen as 'old technology' and replaced by the newer format.

\section{E-LEARNING IN DENTISTRY}

Section A: Teaching and technology

1. A description of the new technologies used in transforming dental education

2. Seeing is believing: dental education benefits from developments in videoconferencing

3. Webcasting: casting the web more widely

4. Top of the pops - CD-ROM and DVDs in dental education

Section B: Informatics: better informed by systems and services

5. Better informed: an overview of health informatics

6. Better informed in clinical practice a brief overview of dental informatics

7. Digital clinical records and practice administration in primary dental care

Section C: Impact of e-learning in

dental education

8. Remember the days in the old school yard: from lectures to online learning

9. An intricate web - designing and authoring a web-based course

10. The many faces of interaction

11. Supporting the learner and teacher online

12. Making a mark - taking assessment to technology

13. Continuing professional development and ICT: target practice

14. Assuring quality

Section D: A connected future

15. Nine years of DentEd: a global perspective

16. A vision of dental education in the third millenium

CD-ROM (compact disc read-only memory) was introduced in the mid-1980s as a development by N. V. Philips of its successful CD audio format. On the basis of 'if sound, why not data? And if data, why not images?', ${ }^{1}$ it seemed an excellent medium for education. Its benefits for education were explained as: 'CDROM's $640 \mathrm{Mb}$ of storage opened up real possibilities for courseware development and packaging of myriad information if you could process that information and decode and display digital video material in real-time. ${ }^{1}$

Initially, its storage capacity attracted the attention of the publishers of encyclopaedias and other reference books

Visiting Professor, UCL Eastman Dental Institute, 256 Gray's Inn Road, London, WC1X 8LD; ${ }^{2 *}$ Professor of Dental Education, Centre of Flexible Learning in Dentistry, King's College London Dental Institute, Floor 3, Strand Bridge House, 138-142 Strand, London, WC2 $1 \mathrm{HH} ;{ }^{3}$ Emeritus Professor of ICT in Education, Department of Education and Professional Studies, King's College London/Senior Research Fellow, King's College London Dental Institute, Floor 3, Strand Bridge House, 138-142 Strand, London, WC2 1HH

${ }^{*}$ Correspondence to: Professor P. A. Reynolds Email: p.a.reynolds@kcl.ac.uk

\section{Refereed Paper}

DOI: $10.1038 /$ bdj.2008.106

${ }^{\oplus}$ British Dental Journal 2008; 204: 203-207 and, when it was launched, this was the first application proposed for CD-ROMs leading to the comment: 'This might explain why, within five years, 80\% of these discs were located in libraries, mainly with academic and professional

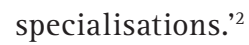

Another similar application that emerged was the use of CD-ROMs as a photo library. Indeed one, an early initiative in dentistry, was a disc from one of the teaching establishments containing dental radiology images. ${ }^{3}$ This was sent to all students who nevertheless had to use it in conjunction with a paper-based course.

Although useful, the applications described so far in this paper are static applications, ie they do not take full advantage of the medium's potential, especially its interactivity and ability to store data in different formats. In the opinion of one author:4 "As soon as a computer is connected to any integrated media source, eg CD-ROM, the potential opens up for the computer to do far more than fulfil the stop-start role.'

It is this combination of functions together with its ability to store text, audio, images and video that has enabled the CD-ROM to be seen as a 


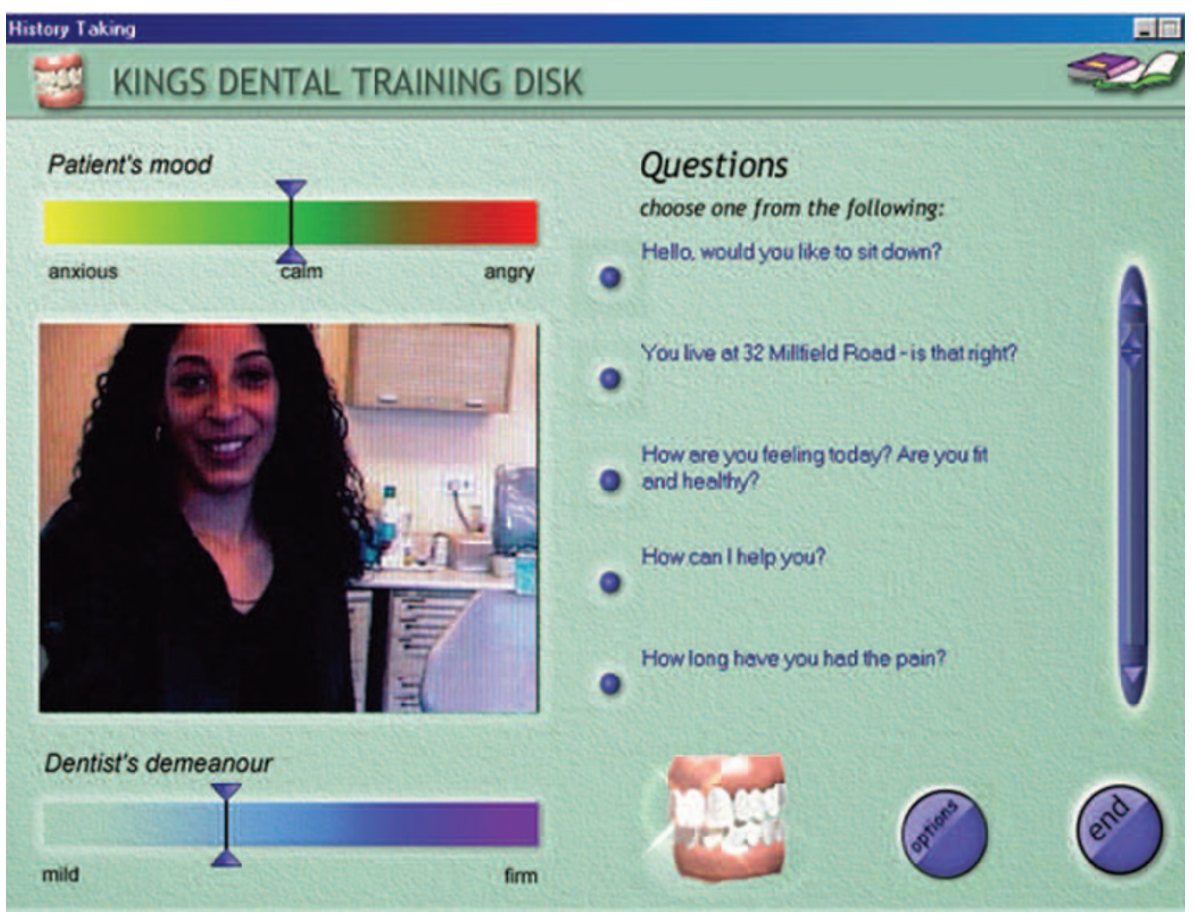

Fig. 1 Screen shot of communications CD-ROM

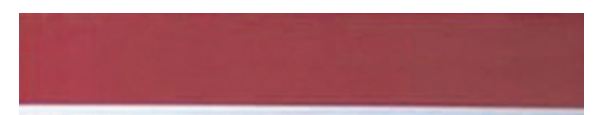

M.MINN'S INTERACTIVE CLINICAL ANATOMY HEAD AND NECK

Patricia A Reynolds - Peter H Abrahams

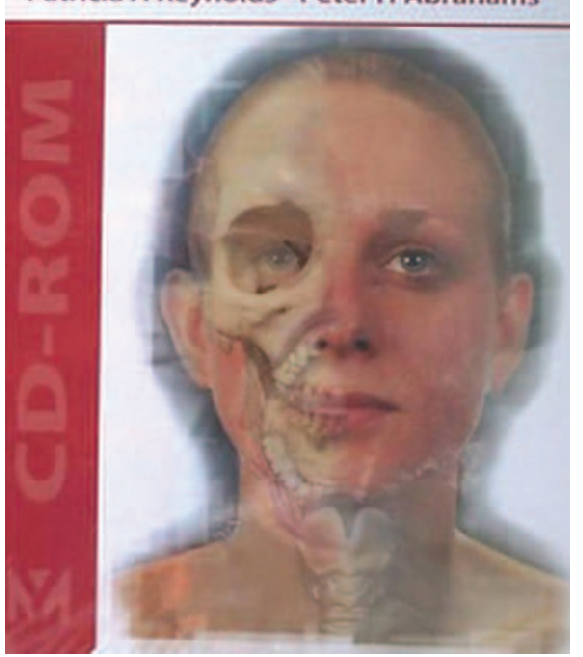

Fig. 2 Cover of McMinn's interactive clinical anatomy: head and neck ${ }^{11}$ stimulating learning resource. ${ }^{5}$ Its attraction as an education and training resource has been increased by integrating it with the updating and interactive capabilities of telecommunications. ${ }^{5}$

The impact of CD-ROMs has been helped considerably by subsequent integration into PCs and laptops, leading to the claim that its development was the event that opened up the world of interactive media... adding the video and audio to computer-mediated instruction.' ${ }^{6}$

CD-ROMs were seen as having narrative, interactive and participative functions. However, a great many CD-ROMs deliver the first two, but few offer "genuinely participative functions." It was also claimed that students participate by creating and doing, eg writing and drawing. This may explain why CD-ROM variants CD-R (compact disc recordable) and $\mathrm{CD}-\mathrm{RW}$ (compact disc rewriteable) have roles. ${ }^{4}$

\section{CONTENT AND AUTHORING}

To be useful, CD-ROM theory and technology have to be translated into a device that will deliver teaching and material in a way that makes a major contribution to a student's learning experience and ultimate success. CD-ROM has the advantage of being a fully integrated digital medium, ie it has the ability to mix sound, video, graphics, animation, speech and text together with interactivity. By fully realising these properties, the CD-ROM developer should be able to produce an imaginative, creative and stimulating pedagogic resource.

Exciting though this may seem, there is still the distinct likelihood that a CD-ROM may still not be fit for purpose, a problem neatly summed up in the claim that: 'Many CD-ROMs are poorly constructed, consisting simply of a mishmash of images, sounds and video that offer little more than light entertainment." Either that or they are the repository of masses of information, cf reference books, or simply store printed material.

Despite the comment that entertainment should play a part in the impact of a CD-ROM, its multi-media potential helps students to both memorise and assimilate information. ${ }^{8}$ However, it should not be assumed that to be effective, educational CD-ROMs need to have the entertainment value of 'Hollywood Blockbusters'. Nevertheless they should be an interactive resource that contributes to 'the total learning package'. The needs of, and benefits to the student must, therefore, be paramount. The media should not be allowed to obscure the message and, when designing an educational CD-ROM, priority must be given to well presented and relevant content. ${ }^{8}$

In the opinion of the authors of this article, a CD-ROM's content should typically include some or all of the following:

- Tutorials

- Games

- Simulation

- Research

- Creating a dialogue

- Problem solving.

Creating these involves three stages - storyboarding, scripting and programming. The storyboard takes the initial idea and concept and turns it into the detailed pictorial scenario for the programme from which the script can be written and the illustrative content determined and resourced. Authoring software is then used to convert the material into digital data for storing on the disc.

\section{DISCOGRAPHY}

A large number of CD-ROMs have been developed for use in dental education, some by a number of academic bodies, some as collaborations between academic bodies and commercial organisations, and some by either private companies or public bodies such as the Department of Health for England. 
Examples of the institute-produced discs are programmes for dental communications and a prescription game. The dental communications programme ${ }^{9}$ forms part of one institution's Introduction to clinical science course 2001 and uses techniques such as multi-choicing, questions and answers, animation and role-playing to show students the problems in and importance of communicating with patients and in putting them at ease when making an initial diagnosis (Fig. 1). It takes into account whether the patient is male or female and their mood during history taking, their state of health and the nature of their dental complaint(s). Produced by a multi-disciplinary team drawn from social and behavioural sciences, dentistry, education and IT, the disc's aims are to improve dentist-patient communications through an interactive programme, which enables students to develop and test their strategies for communicating with patients in a simulated dentist-patient clinical session.

\section{Development of materials}

During the production of the programme, experienced professional role players (actors) were employed to provide the 'patient' for the CD-ROM. Three role players took part, one male and two female. Each acted out the patient part of the storyboard five times, portraying different emotional levels on each occasion. The five different levels were:

- Calm

- Mildly anxious

- Very anxious

- Mildly angry

- Very angry.

On each occasion the patient gave the same answers to questions on the medical history and broadly similar responses. Additional phrases and changes in tone of voice and non-verbal behaviour were used to denote emotion. Similarly, students were (and are) able to change their own demeanour from mild to firm by moving a cursor.

Additional recordings of non-storyboard pieces were made for each 'patient' for inclusion as hidden elements within the CD-ROM. For example, the patient was recorded walking out of the dental surgery, or hitting the camera.

\section{Evaluation - trials with students}

The attitude of the students towards this learning experience was evaluated using the Theory of Planned Behaviour (TPB), a model of behaviour derived from research in social psychology. ${ }^{10} \mathrm{~A}$ questionnaire based on the TPB tested the following:

Attitude towards communicating well with patients over the next six months was measured using six semantic differential scales (ie, boring-interesting; harmful-beneficial; unpleasant-pleasant; unenjoyable-enjoyable; worthless-valuable; unimportant-important), scored -3 to +3 .

Subjective norm was assessed in relation to four groups of people who were important to the student: their fellow students, their clinical supervisors, their patients, and their family. Each item was scored -3 to +3 and the scale scores summed.

Perceived behavioural control was measured by four items scored from -3 to +3 .

Behavioural intention. This scale comprised four items.

Table 1 shows the scores of the students for the TPB tests, following their work with the CD-ROM. The students showed a very positive attitude towards communicating with patients, they believed it was important and valuable. They also believed that their colleagues and staff believed it was important that they communicate well with patients (subjective norm). The perceived behavioural control scores suggested that the students believed that they had a degree of control over their ability to communicate well with their patients. Finally the students showed a positive behavioural intention to communicate well with their patients.

\section{In the neck}

The second group of CD-ROMs - those produced by external organisations, but with considerable input from an academic body - can be illustrated by the "Head and Neck Anatomy 2'11 disc (Fig. 2).

The CD-ROM is virtually a textbook of the anatomy of the head and neck. Its contents cover anatomical terms and definitions, embryology, histology, systems overview, special clinical sections, and interactive anatomy. Its educational value is revealed at the very beginning of the programme: "The anatomy of the head and neck poses a particular challenge for the student. The relationships of adjacent anatomical structures are especially difficult, and an ability to visualise in three dimensions is absolutely essential to success in studying this area of the body.'

The image and interactive properties of CD-ROM are invaluable in overcoming this problem and the disc uses them to good effect. The text provides narrative and explanation, but, on the basis of 'one picture's worth a thousand words', it is also the gateway to pictorial depiction. Embedded in the text are hyperlinks to slides, movies and diagrams that provide graphic depictions of parts of the anatomy, dental conditions, treatment and operations. The still images are labelled such that specific areas are highlighted, allowing students to study them in close-ups, a facility enhanced by the ability to zoom in even closer. The inclusion of questions and answers, quizzes and a fully-indexed glossary complete what is a very comprehensive, stand-alone teaching aid.

\section{CD-ROMs for use in dental continuing professional development}

A number of UK dental schools have developed programmes for undergraduates, covering topics such as complete dentures $^{12}$ and orthodontic assessment, ${ }^{13}$ and elsewhere in the world large numbers have been developed for this

\begin{tabular}{|c|c|c|c|c|}
\hline & $\begin{array}{l}\text { Attitudes } \\
\text { (6 items) }\end{array}$ & $\begin{array}{l}\text { Perceived behavioural } \\
\text { control } \\
\text { (8 items) }\end{array}$ & $\begin{array}{l}\text { Subjective norm } \\
\text { (4 items) }\end{array}$ & $\begin{array}{l}\text { Behavioural intention } \\
\text { (4 items) }\end{array}$ \\
\hline Mean & 13.49 & -1.91 & 1.40 & 1.75 \\
\hline SD & 4.42 & 2.32 & 3.80 & 1.77 \\
\hline
\end{tabular}




\begin{tabular}{l|l|}
\hline \multicolumn{2}{l}{ Table 2 Typical titles of CD ROM CPD programmes produced between $\mathbf{1 9 9 4}$ and 2002} \\
\hline Title & Date published \\
\hline Safequest... a look at cross infection control & 1998 \\
\hline Oral ulcers & 1998 \\
\hline Fissure sealants & 1999 \\
\hline The X-ray files & 2000 \\
\hline Management of traumatised incisors & 2000 \\
\hline Dental photography & 2001 \\
\hline Screening for oral cancer and pre-cancer in general dental practice & 2002 \\
\hline Assessing the periodontium & 2002 \\
\hline
\end{tabular}

\begin{tabular}{|c|c|c|c|c|c|}
\hline Media component & Humanities & $\begin{array}{l}\text { Social } \\
\text { sciences }\end{array}$ & Science & Technology & $\begin{array}{l}\text { Maths \&t } \\
\text { computing }\end{array}$ \\
\hline Course programmes on TV & 83.7 & 68.5 & 68.9 & 52.9 & 45 \\
\hline Video programmes sent to you & 95.1 & 88.2 & 92.3 & 81.9 & 78.2 \\
\hline Course programmes on radio & 59.5 & 46.3 & 38.4 & 25.4 & 26.9 \\
\hline $\begin{array}{l}\text { Audio cassette } \\
\text { sent to you }\end{array}$ & 89.2 & 83.5 & 76.6 & 68.1 & 69.7 \\
\hline $\begin{array}{l}\text { Computer discs, CD-ROMs etc. } \\
\text { sent to you }\end{array}$ & 78.9 & 80.7 & 86.1 & 95.1 & 96.7 \\
\hline $\begin{array}{l}\text { Online materials and resources } \\
\text { you can access }\end{array}$ & 69.2 & 68.6 & 75.7 & 81.3 & 84.6 \\
\hline $\begin{array}{l}\text { Online courses, email, } \\
\text { conferencing }\end{array}$ & 58.4 & 64.8 & 71.9 & 81.3 & 78.8 \\
\hline
\end{tabular}

purpose. $^{14}$ There are approximately 33,500 registered dentists in the UK,,$^{15}$ all of whom are legally required to undertake continuing professional development (CPD). It is perhaps unsurprising, therefore, that the use of CD-ROMs has been widespread as a means of providing CPD. Dental companies have produced educational CD-ROMs to provide CPD to dentists. The programmes have been both for distribution free of charge $\mathrm{e}^{16}$ and as commercial ventures. ${ }^{17}$ Typical of the latter are programmes on 'PULP affliction' and 'Screening for oral cancer and precancer': versions are available with a verifiable module. In the recent past, some of the discs have been for simultaneous use with online programmes and have enable users to overcome the limitations of lack of band-width when online. ${ }^{18}$ However, in England the greatest number of dental CD-ROMs, both in terms of the range of titles and numbers distributed, were developed to provide CPD to dentists working in primary dental care in the NHS.

Over thirty different CD-ROM programmes, covering virtually all aspects of clinical dentistry were developed, evaluated and distributed, initially by the Department of Health for England and, until 2002, by the National Centre for the Continuing Professional Education of Dentists (NCCPED) as part of a distance learning initiative for general dental practitioners (GDPs). The programme was funded under the terms of section 63 of the 1968 NHS Act which permits the Secretary of State for Health to fund the continuing professional education of dentists. ${ }^{19}$

This initiative began in 1990 as a response to a national survey of the CPD participation by GDPs in England, which indicated a need for home/work-based CPD materials. ${ }^{20}$ Thirty-two different programmes were produced between 1994 and 2002; typical titles are shown in Table 2.

All titles underwent a standardised evaluation by a minimum of 50 dentists per programme before they were made generally available. The results of the evaluations of the early programmes were published in peer-reviewed journals. ${ }^{21-25}$ The CD-ROMs in the series cover virtually all aspects of clinical dentistry and were/are available free of charge to all dentists working in NHS primary dental care in England. 26,500 were distributed in one year alone (the financial year 2001/2002). ${ }^{26}$ They are unique in terms of the rigorous pre-distribution evaluation and assessment, wide range of topics covered and numbers distributed: all promoted (and promote) interactive learning.

\section{CD-ROMS AND BLENDED LEARNING}

CD-ROMs can play an important role in blended learning, which is the combination of e-learning and face-to-face instruction. For example, CD-ROMs have been used before, during and after traditional CPD attendance courses.

The benefit of using a CD-ROM on the topic of the course before an attendance class is that it provides a review of the 'science' and methodologies to be covered. This is particularly useful prior to CPD 'hands-on' courses, as with the 'theory' covered in the participants' own time and in advance of the attendance element of the 'blended course', participants can spend more time actively using the 'hands-on' facilities and can maximise the time that they are actively carrying out procedures.

During attendance courses, the ability of a CD-ROM to store vast quantities of high quality images can be harnessed in a number of ways. From the point of view of the teacher/lecturer/educational facilitator, it has largely removed the need to transport carousels of $35 \mathrm{~mm}$ slides from class to class and, in tandem with software such as PowerPoint, has led to the development of new styles of teaching. When videoconference links are used to enable speakers/teachers from distant sites to address audiences/classes, the use of local projected images from 
CD-ROM can be used to overcome the problem of poor image quality and enable low band-width links to be used. ${ }^{27}$

After taking part in attendance courses, participants can use CD-ROMs to provide aide-memoires and can refer to them to check information or images.

\section{EFFECTIVENESS}

As far as dental education is concerned, there have been a number of studies and papers on the topic of 'effectiveness', including Schleyer and Johnson (1999), ${ }^{14}$ Kay (2002), ${ }^{28}$ and Renson (2002). ${ }^{29}$ An important point is that unlike webbased programmes, CD-ROMs cannot be updated, but at present at least, they provide better image quality and, unless the user has access to broadband, do not incur expensive call charges.

Table 3, taken from the report of a study by The Open University ${ }^{27}$ amongst its students, shows the rating of different media components by types of subjects. It should not be surprising that CD-ROM scores higher in the science, technology and maths courses, which are more likely to use this resource and whose students are more likely to be computer literate.

Kirkwood later comments on 'software components for independent learners, for example, enabling learners to actively explore, manipulate and interact with resources where these forms of engagement are central to the learning process. ${ }^{27}$ He then quotes a science student's illustrative comment: 'one of the best ways of learning; you're permanently interacting with the CD-ROM; makes learning fun.'

\section{DISC ENDS}

The CD-ROM has made a major contribution to the development of teaching practice and the greater availability of educational material for students. However, there is now some doubt as to its future as a teaching medium. The advent of DVD with a maximum storage capacity of 17 gigabytes as against
CD-ROM's 0.6 gigabytes means that there is now a considerable - and fashionable - rival. DVDs combine the best features of laser disc and CD-ROM and provide a multi-media platform that can deliver high quality, full motion video and better-than-CD audio. They can be a highly interactive, with an on-screen navigation capability with branching which allows the selection of a particular lesson from a menu or the quick navigation of programme content. Provided it incorporates the relevant additional content, users can select their native language for video scenes and audio tracks.

With a computer or video player, a DVD can not only accommodate the same types of data as CD-ROM, but also present it in a superior, more lifelike manner. In addition, it allows students to create their own versions.

A problem could be that DVDs may well demand Hollywood Blockbusterstyle production values with commensurate costs. This may be the reason why there are currently few DVDs available for dentistry or other disciplines. One such example is the course on 'Pulp afflictions'30 that aims to review students' 'understanding of the principles of endodontic practice.' Since the advent of high density DVD, ever more detailed and extensive material can be viewed.

1. Paine N, McAra P. Interactive multimedia technology: a summary of current developments. In Lathem C, Williamson J, Henderson-Lancett J (eds) Interactive multimedia practice and promise. London: Kogan Page, 1993.

2. Frylinck J, Raitt D. Librarians catch the multimedia wave. In Lathem C, Williamson J, Henderson-Lancett J (eds) Interactive multimedia practice and promise. London: Kogan Page, 1993.

3. Dental radiographic images (CD-ROM). MSc in Dental and Maxillofacial Radiology by Distance Learning, King's College London Dental Institute, 1995.

4. Heppell S. Eyes on the horizon, feet on the ground? In Lathem C, Williamson J, HendersonLancett J (eds) Interactive multimedia practice and promise. London: Kogan Page, 1993.

5. Mason R. Globalising education trends and application. London: Routledge, 1998.

6. Inglis A, Ling $\mathrm{P}$, Joosten V. Delivering digitally: managing the transition to the knowledge media. 2nd ed. London: Routledge Falmer, 2002.
7. Aldrich F, Rogers Y, Scaife M. Getting to grips with interactivity. Helping teachers assess the educational value of CDROMs. Br J Educ Technol 1998: 29: 321-332.

8. Eaton K A, Hammick M.Distance learning materials for dentists - a users guide to quality. Br Dent J 2003: 194: 253-256.

9. Cox M, Newton T, Harper J, Reynolds P, Thorogood N. King's College Dental Institute dental communications CDROM. London: King's College London Dental Institute, 2001.

10. Ajzen I. The theory of planned behavior. Organ Behav Hum Decis Process 1991; 50: 179-211.

11. Reynolds P A, Abrahams P H. McMinn's interactive clinical anatomy: head and neck (CD-ROM). London: Mosby Elsevier, 2002.

12. Pollard D, Walmsley A D. GEORGE: using a PC to mimic the clinic situation. Dent Update 1994; 21: 373-378.

13. Grigg P, Stephens C D. Computer-assisted learning in dentistry: a view from the UK. J Dent 1998. 26: 387-395.

14. Schleyer T, Johnson L A, Pham T. Instructional characteristics of online continuing education courses. Quintessence Int 1999; 30: 755-761.

15. General Dental Council. Dentists register 2006. London: General Dental Council, 2006.

16. Kavo $\mathrm{GmbH}$. Edulearn - a new approach to dental education. CDROM. Kavo EWL, Leutkirch in Allgau.

17. The Dental Channel website. http://www.dentalchannel.co.uk (accessed 22 May 2006).

18. Eaton $\mathrm{K}$ A. The integrated use of videophones and $C D$ roms to overcome bandwidth limitations during videoconferenced lectures. Technol Health Care 2001; 9: 320

19. Eaton K A, Veale $B$, Rothwell PS. What are section 63 'approved' courses and how are they organised? Br Dent J 1992; 173: 307-311.

20. Mouatt R B, Veale B, Archer K. Continuing education in the GDS. An England study. Br Dent J 1991; 170: $76-79$.

21. Long A F, Mercer P E, Stephens C D, Grigg P. The evaluation of three computer-assisted learning packages for general dental practitioners. Br Dent J 1994; 177: 410-415.

22. Pollard D J, Davenport J C. An evaluation of training general dental practitioners in partial denture design using a computer-assisted learning program. Br Dent J 1994; 177: 405-409.

23. Porter SR, Telford A, Chandler K et al. Computerassisted learning for oral manifestations of HIV disease. Br Dent J 1996; 181: 173-177.

24. Downes P K, Eaton K A. The evaluation of Safequest - a computer-assisted learning programme on cross-infection control for the dental team. Br Dent J 1997; 183: 333-337.

25. Pollard D J, Kajan V, Porter S R, Scully C. Evaluation of computer assisted continuing education in oral ulceration. J Dent Res 1999; 78: 450.

26. Best $H$, Eaton $K A$, Plasschaert A et al. Continuing professional development - global perspectives: synopsis of a workshop held during the International Association for Dental Research meeting in 2003: Part 1. Eur J Dent Educ 2005; 9: 59-65.

27. Kirkwood A. Understanding independent learners' use of media technologies. Open Learning 2003; 18: 155-175.

28. Kay E J, Silkstone B, Worhington H V. Evaluation of computer aided learning in developing clinical decision-making skills. Br Dent J 2002; 190: 554-547.

29. Renson E. Is computer-assisted learning effective for GDPs? Primary Dent Care 2002; 9: 79-80.

30. Robinson B, Gould A. Pulp afflictions (CDROM) 2005. London: Dental Channel. www.dentalchannel.co.uk (accessed 8 February 2007). 